\title{
EFFECT OF TOTAL COMPENSATION ON PAY SATISFACTION IN TELENOR COMPANY PAKISTAN
}

\author{
RAZA MUBARAK $^{1}$, IRUM KHATTAK ${ }^{2}$, MUHAMMAD ZEESHAN KHATTAK $^{3}$ \\ ${ }^{1}$ Department of Management Science, Abdul Wali Khan, University Mardan, \\ Khyber Pakhtunkhwa, Pakistan \\ ${ }^{2}$ Department of Management Science, Abdul Wali Khan, University Mardan, \\ Khyber Pakhtunkhwa, Pakistan \\ ${ }^{3}$ Department of Management Science, Institute of Management Sciences, \\ Khyber Pakhtunkhwa, Pakistan \\ Email: irum@awkum.edu.pk
}

\begin{abstract}
The purpose of the study is to examine the impact of total compensation on pay satisfaction of employees in Telenor Pakistan. Data was collected through questionnaire and interview. It is revealed that fixed pay components such as merit increments are prominent unlike seniority bonuses in Telenor because of the fact that the company has a flexible pay structure of broadband. Broadband offer flexibility and easy salary progression as employees is not promoted to another grade but moved within band (in-grade promotion). Among the variable pay dimensions, goal based pay, accurate information use related to salary decisions, employee rights concern and information sharing regarding employee related decisions are much satisfactory at Telenor compared to other components of variable pay. In case of benefits, employees were highly satisfied with allowances, welfare programs and consider it reason for their motivation and stay in Telenor. Overall, equity in Telenor is nearly in balance and pay satisfaction over various components of total compensation has an nutshell positive effect in creating strong sense of belonging of employee with their organization.
\end{abstract}

Keywords: Fixed; Variable; Pay satisfaction; Benefits; Telenor; Pakistan

1. Introduction. A safety Monetary incentives have an important function of a mediator for motivation and have a considerable role in enhancing the overall performance of employees. Compensation systems affect both the compensation policies of an organization and the behavior of employees [1]. Pay satisfaction is becoming an important issue during the past years because of the leveling and decreases in salaries, wages, adjustments and incentive pay $[2,3,4]$. When employees are more satisfied with pay and understand how it is determined, they are less likely to question it. Job satisfaction is perceived to be linked directly to pay satisfaction in every feild [5] that lead towards the organizational effectiveness. Workers with high level of job satisfaction are more likely to be creative, innovative, flexible and loyal and it further results in a workforce that is motivated and committed to higher quality of performance. On the other hand, evidence suggests that dissatisfaction leads to negative effect in behavior such as detachment from work, turnover and increasing intentions to leave and absence [6]. The effect of job satisfaction on the organizational performance and effectiveness makes the exploration of job satisfaction very important. Considering the present economic crisis, it is difficult for organizations to attract, retain and motivate talent by offering competitive salaries, hence it is important to consider other determinants of pay satisfaction i.e. compensation and benefits. Further, division of satisfaction has been made as intrinsic and extrinsic in literature. Extrinsic satisfaction ensues from rewards and recognition (monetary and non-monetary) as well as career advancement $[7,8]$. The focus of the 
present study is on extrinsic satisfaction and how it affects employees in a company.

1.1. Problem statement. The current study examines the impact of total compensation on pay satisfaction of employees inTelenor Pakistan (cellular mobile operator).

\section{Literature Review}

2.1. Compensation. Compensation is very crucial to both, the employees and the employers or organizations [9]. It is one of the major financial expenditure that an organization incurs and plays a significant role in motivating employees as well, which is why significant amount of research has been done on it $[10,11,12]$. According to Deluca [13] and Rajkumar [14] compensation is defined as pay, reward, remuneration or salary and wage management. Compensation can be direct and indirect payments, monetary and non-monetary rewards and cash and non-cash payments. Compensation in monetary form is seen as a measure of justice; therefore, mostly it is seen in the form of financial returns and tangible services and is considered as the major source of financial security by the employees [15]. Compensation structure are grouped into two core elements -fixed pay and variable pay [16].

2.1.1. Fixed Pay. Fixed pay, also called as base pay, has non-discretionary nature and does not change with performance or accomplishment of achievements. It enhances loyalty, steadiness and long term orientation of employees because it provides motivation not based on short-term tagets or revenues [16]. It is evident that sales people compensated through fixed salary showed higher job satisfaction and decreased turnover rate than their counterparts who were remunerated through incentive pay showed dissatisfaction with their pay [17, 18]. Further, seniority can also be used as a predictor to determine the actual pay. It can be argued that age and seniority do lead to increased performance, as an employee seeks experience his or her ability to perform a job increases which would lead to a better organizational outcome. According to Sharma \& Bajpai [18], the correlation between pay and seniority depict that organizations are compensating for merit. Seniority bonuses also are the component of fixed salary which is usually given to employees after serving the organization for certain time period (experience). Merit increments are also added in base pay after evaluating the past performance of an employee. These are not earned again as in the incentives case, in which incentives are re-earned because they are given to achieve certain objectives [16].

2.1.2. Variable Pay. Variable pay, also called pay at risk, changes directly with the level of performance or results achieved [16].Variable compensation is a one-time earning that must be re-established and re-earned each performance period. It can be short-term or long-term [16]. A certain amount of pay, to meet ones needs, is crucial for people. However, beyond that level flexible pay schemes play a significant role in pay satisfaction. Flaherty and Pappas [19] found that employee have lower satisfaction and higher turnover intention with a fixed salary unlike salespeople having higher satisfaction and lower turnover intention when given incentives.

Flexible pay system could be achieved by increasing the variable pay and short or medium term deferred income in the compensation package of the employee. Variable pay distribution is uncertain and it consists of bonuses, incentives, goal-based pay, overtime, gain sharing, etc, where as deferred income are sums that are blocked for a certain period of time before becoming available and it includes employee stock ownership plans, company saving schemes, profit sharing etc. Researchers discovered that flexible pay schemes can result in a positive relationship and increased employee satisfaction [20]. However, flexible pay schemes approaches differ considerably from one organization to another. Based on expectancy motivation theory, a flexible benefits system has a significance in context of expectancy of motivation as flexible benefits provide staff with a freedom to adopt or mould their reward package according to their personal circumstances [21, 22].

2.2. Benefits. Compensation alone cannot direct an employee's performance to a certain level unless it is accompanied by employee benefits. Benefits are crucial for the organizations because they are used to attract and retain good and talented workers. On the other hand, for employees, benefits carry more importance because they rely on benefits such as medical subsidies, vacations, and retirement etc to secure their financial well-being. Benefits vary with respect to the seniority of the employees in the organization and this makes the workers reluctant to change their jobs [23]. 
Benefits are made up of three major components. Firstly, benefits consist of the allowances part which are mainly the housing, food and transportation allowances. The second part of benefits consists of employee welfare programs and recreational opportunities concerning tickets for various entertainment events, family assistance, scholarships. Included to it are also flexible work timings (telecommuting, nonpaid time off etc), drug counseling, jury duty, vacations, child and elder care and a fulfilling work environment. Lastly, it includes pension plans, disabled workers allowance, medical insurance, retirement plans, life insurance and savings plan [24]. For high employee satisfaction, managers who provide benefits need to collaborate with employees to identify the personal needs on the basis of which they can provide them with benefits. Theory of 'Reasoned Action' claims employee's belief over the value benefits provide and develops a positive attitude of employees towards these benefits which in turn determines the satisfaction level. This satisfaction then leads to their commitment with the organization which is based primarily on their pay satisfaction [25]. Therefore, benefits create an economic exchange with organizations because employers get better quality work and employees want better benefits in their pay package to be satisfied and are willing to put time and effort for it [24].

2.3. Pay Satisfaction. Pay is considered as episodic payment to an employee due to the employee and employer relationship (employment contract). Pay satisfaction has a narrow scope than job satisfaction but it is the most important factor that can affect organizational outcomes. Dissatisfaction with pay may lead to reduced motivation, low performance of employees and increased absenteeism and turnover. During many years' observations, it was noticed that monthly pay, that were obtained by employees, were favored in contrast to incentive pay which varied in context [18].

The most common and well-known models which help in determining pay satisfaction is the Equity Theory [26] and Discrepancy Model [27]. These models elucidate employees' drawing out satisfaction from their compensation plans. Equity theory's roots lie in the concept of social comparison where an employee comparison of input/output ratio can be done with employees in the same organization as well as other organizations and if the ratio is lesser or smaller than that of another employee, it results in inequity and dissatisfaction and employees are motivated to lessen the inequity. These perceptual comparisons can be done with factors such as pay, time-off, benefits and recognition [26, 24]. The theoretical basis of the discrepancy theory, proposed by Lawler [27] advocates the concept of social comparison, just the same as equity theory. In addition to that, Vroom's expectancy theory is also utilized to formulate discrepancy theory. According to Vroom [28], employee's behavior is motivated by pay if it leads to desirable outcomes and the employee gives it a high valence. Discrepancy theory focuses on what an employee expects and the reality and the discrepancy between the two affects the employee's satisfaction levels. This highly depends upon the personal needs and aims of the employee as well as what he values, his beliefs and expectations from the outcomes of the job. Pay satisfaction depends on the difference between the perceived pay and the amount of pay a person received $[17,29,1,18]$.

Heneman and Schwab [2] have been considered the first amongst researchers to identify the multiple dimensions of pay satisfaction and gestate its constructs including pay level, pay raises, benefits structure and administration. Pay satisfaction differs according to levels of management and departments as the job descriptions also vary from level to level and department to department [30]. Pay satisfaction is affected by a number of variables which as identified by Heneman and Schwab [2]. The performance level increases with pay raises as the effect is direct between the two. The raise in most of the organizations is considered to be a promotion or a step forward in taller hierarchies, showing increase in cumulative pay. However, in many organizations the increase in the pay can be non-cumulative depending upon targets or if the pay structure is commission-based. The pay raises are different at senior, middle and lower level of management. The benefit sets can also be fixed or flexible depending upon the pay package for the employees. Mostly flexible benefits basket is used by the organic organizations and fixed benefits in mechanistic structure. Generally defined benefits at all levels are considered easy to monitor but increases cost, providing all benefits to all employees even when they do not require it. Such benefit plans also fail to provide meaningful benefits to employees as they have varying age, needs, interests and lifestyle. The employees at high and senior level want their pay benefits to be flexible choosing from the basket and generally low level employees have fixed and defined benefits. So pay compensation is dependent on level, raise and benefits which in turn effects the 
organizational commitment of employees. These factors act as motivators, increasing positive correlation of high performance and high commitment from bottom to top i.e. for low to senior levels of employees maintaining a high performance organization.

2.4. Theoretical Framework. In the light of above literature, this study is focused on impact of various components of compensation and benefit on pay satisfaction. Theoretical framework for the study is estabilished given in Figure 1.

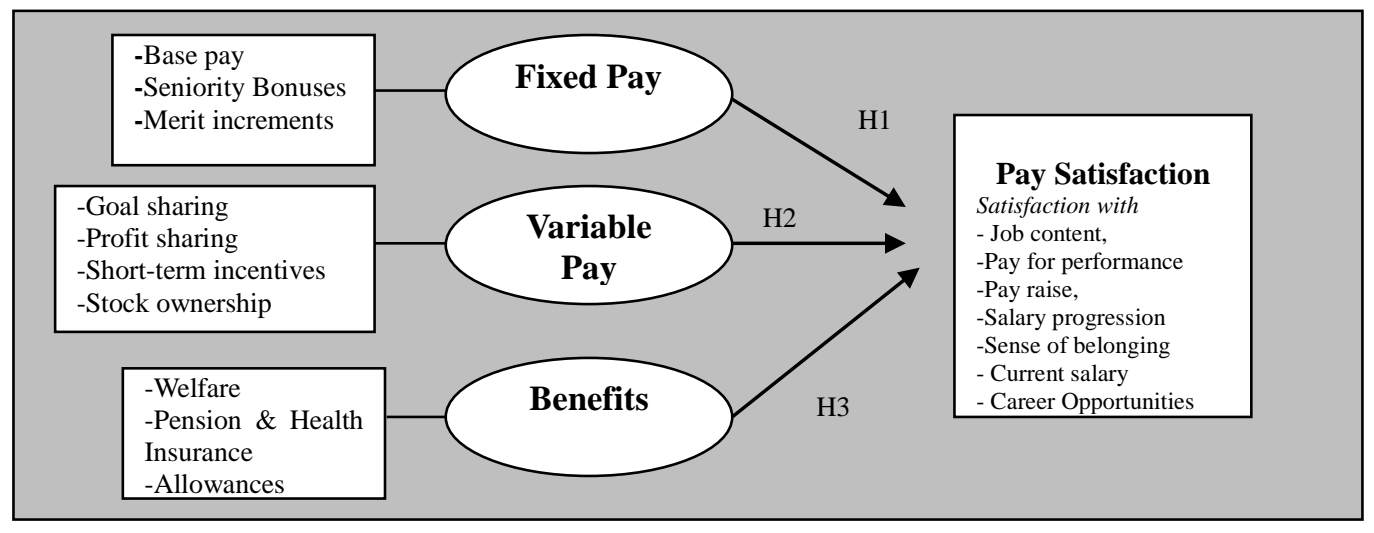

Figure 1. Theoretical Framework

\subsection{Hypothesis}

H1: Fixed pay is positively related to pay satisfaction

$\mathrm{H} 2$ : Variable pay is positively related to pay satisfaction

H3: Benefits are positively related to pay satisfaction

3. Methodology. The study was carried on a sample of 30 employees working at Islamabad headquarter of Telenor company. The simple random techniques was selected. The data was collected through questionnaire and interview. The questionnaire was designed on 5-likert scale $(1=$ strongly disagree, $2=$ disagree, $3=$ neutral , $4=$ agree and $5=$ strongly agree).

\section{Analysis and Discussion}

4.1.Results for Fixed Pay. The question "I am receiving fair salary if considered the experience I have", shows that employees at Telenor are not compensated on the basis of experience or seniority mostly. 50\% of respondents disagree with it shows that there is no such rigid or beurocratic hierarchy, where employees are remunerated just on the basis of their relationship (time in position) with the organization, rather employees are remunerated according to their contribution towards organization. Pay for performance concept prevails in this organization which indicates a flexible and somewhat flat structure which would be needed in today's competitive environment. This was also supported by the interviewee that they have broad band structure with six bands and defined pay ranges. This pay structure laid emphasis on employee contribution towards organization rather than just spending time period with organization.

Table 1

Results for Fixed Pay Dimensions

\begin{tabular}{|c|c|c|c|c|}
\hline & $\begin{array}{c}\text { Responses } \\
\text { on Fixed Pay Dimensions }\end{array}$ & Agree & Neutral & Disagree \\
\hline 1 & Experienced Based Salary & $30 \%$ & $20 \%$ & $50 \%$ \\
\hline 2 & Seniority Bonuses & $13 \%$ & $67 \%$ & $20 \%$ \\
\hline 3 & Merit Increment & $54 \%$ & $33 \%$ & $13 \%$ \\
\hline 4 & Merit Increment Frequency & $47 \%$ & $33 \%$ & $20 \%$ \\
\hline
\end{tabular}

Second question regarding whether seniority bonuses are market competitive indicates neutral responses $(67 \%)$ from the respondents. This means that this factor doesn't contribute towards pay satisfaction as 
confirmed by the interviewee that they don't consider the seniority bonuses because they receive salary as a whole and also they have pay for performance culture which negate the seniority bonus concept. Pay for performance as explained by the interviewee at Telenor is contributing towards organization either financial or non financially regardless of the fact that he/she is new or old at organization would get the rewards. Third question regarding merit increments results (54\% satisfied over merit increments) also supported this notion.

Last question of fixed pay "Merit increments are given frequently", shows that approximately $50 \%$ of employees receive the merit increments on frequent basis, which has a positive impact on employees motivation and satisfaction. This helps in creating positive line of sight towards performance and reward. If the reimbursements are not frequent this would lead to dissatisfaction among employees revealed from interview.

From the above discussion it is clear that $\mathrm{H} 1$ of the study is valid because merit increments are part of fixed pay which contributed towards the pay satisfaction of employees. Rewarding past performance motivates employees to continue his/her performance up to the mark in order to gain these increments on regular basis which in return help the organization to meet its goals efficiently. Seniority bonuses were not catered because of the fact that the company has a flexible pay structure that of broadband (six bands) which mostly competitive companies adopt in order to cope with the changing market demands. Broadband offer flexibility and salary progression becomes easy as employees is not promoted to another grade but moved within band (in-grade promotion). It has importance in contrast to seniority based culture because it empowered employee which results in quick and effective decision making. Through it the major issue of grade drift is also catered.

4.2. Results for Variable Pay. The employees of Telenor headquarter Islamabad acknowleged their satisfaction level on various factors of variable pay. $26 \%$ were satisfied with profit sharing policies, $25 \%$ with stock options but $28 \%$ were not satisfied over stock options, $50 \%$ were satisfied with goal based pay and $40 \%$ were satisfied with short term incentives. It is noteworthy that $37 \%$ were not satisfied with short-term incentives. Moreover, $44 \%$ were agreed over the statement that accurate information is used to make decisions about employee's salary and $37 \%$ were agreed that concern is shown for employee's rights. Employees also agreed to the notion that reasons related to employees are shared (37\% agreed).

These results aided with interviewee clearly depicted that employee consider some of variable pay dimensions are much satisfactory at Telenor such as goal based pay, accurate information use related to salary decisions, employee rights concern and information sharing regarding employee related decisions. However, stock options was at least satisfactory level. Majority of employees showed satisfaction over profit sharing policies and short term incentives but the number of dissatified employees were considerable. It was revealed in interview that variable pay affect the pay satisfaction of employee positively and it can be increased in case of Telenor if the weak links is given a due consideration. The hypothesis $\mathrm{H} 2$ of the study is validated.

Table 2

\section{Results for VariablePay Dimensions}

\begin{tabular}{|l|l|c|c|c|}
\hline & \multicolumn{1}{|c|}{ Responses on Variable Pay Dimensions } & Agree & Neutral & Disagree \\
\hline 1 & Profit sharing policies & $26 \%$ & $54 \%$ & $20 \%$ \\
\hline 2 & Stock options & $25 \%$ & $47 \%$ & $28 \%$ \\
\hline 3 & Goal based pay & $50 \%$ & $22 \%$ & $28 \%$ \\
\hline 4 & Short-term incentives & $40 \%$ & $24 \%$ & $36 \%$ \\
\hline 5 & $\begin{array}{l}\text { Accurate information used to make employees } \\
\text { salary related decisions }\end{array}$ & $44 \%$ & $31 \%$ & $25 \%$ \\
\hline 6 & Concern shown for employee's rights & $37 \%$ & $35 \%$ & $28 \%$ \\
\hline 7 & $\begin{array}{l}\text { Reasons behind employee related decisions are } \\
\text { explained }\end{array}$ & $37 \%$ & $35 \%$ & $28 \%$ \\
\hline
\end{tabular}


4.3. Results for Benefits. The $53 \%$ employee considered allowances as sufficient, $20 \%$ disagreed and $26 \%$ remained neutral. The disability income protection concept doesnot exist in the company depicted from response rate of $7 \%$ as agreed , 60\% neutral and 33\% disagreed to disability income exists notion. $70 \%$ employees are with the view that welfare programs provided could be increased. Employees are satisfied with Recreational opportunities in Telenor with the arte of 73\%. Further, all employees were with the opinion that benefits is important part of salary (100\% agreed). These results were supported by similar interview results.

Table 3

Results for Benefit Dimensions

\begin{tabular}{|c|c|c|c|c|}
\hline & Responses over Benefits Dimensions & Agree & Neutral & Disagree \\
\hline 1 & Allowances are sufficient. & $53 \%$ & $26 \%$ & $20 \%$ \\
\hline 2 & Disability income protection exists in company & $7 \%$ & $60 \%$ & $33 \%$ \\
\hline 3 & $\begin{array}{c}\text { Types of employee welfare programs provided } \\
\text { could be increased }\end{array}$ & $70 \%$ & $23 \%$ & $7 \%$ \\
\hline 4 & Recreational opportunities are Satisfactory & $73 \%$ & $13 \%$ & $14 \%$ \\
\hline 5 & $\begin{array}{c}\text { All sorts of benefits are important part of my } \\
\text { salary }\end{array}$ & $100 \%$ & $0 \%$ & $0 \%$ \\
\hline
\end{tabular}

Overall, hypothesis three $\mathrm{H} 3$ was also supported with results of interviwee aided with qusetionaire data. Employees were highly satisfied with allowances and considered it important for their stay in Telenor. They acknowledged the welfare programs but showed their desire for its enhauncement. They strongly consider benefit as a part of pay in Telenor and the reason of their motivation and satisfaction. Disability income protection concept is not prevailing in the company.

4.4. Results for Employee Satisfaction. First questions "Do you think that the annual salary of your peers when compared to yours is more?" depicts the equity either followed or not. 50\% agreed that they are receiving less as compare to their peers. And 33\% respondents disagree with it. So employees at Telenor are of the view that they are putting more efforts than their counterparts but receiving less. This result showed that there is a difference between employees' perceived pay and the actual pay, there could be various reasons for it as explained during an interview from one of Telenor employee that every job has varying pay ranges which might differ with other employee as one employee in Telenor might be at start-up stage while other have more time period and skills so results in getting more pay.

Table 4

Results for Employee Satisfaction Dimensions

\begin{tabular}{|c|l|c|c|c|}
\hline & Responses on employee satisfaction Dimensions & Agree & Neutral & Disagree \\
\hline 1 & Annual salary of your peers when compared to yours is more & $50 \%$ & $13 \%$ & $33 \%$ \\
\hline 2 & $\begin{array}{l}\text { The salary of that person is more at work with whom you } \\
\text { most compare yourself }\end{array}$ & $24 \%$ & $32 \%$ & $44 \%$ \\
\hline 3 & $\begin{array}{l}\text { Estimated average annual salary of employees in your region } \\
\text { who are holding jobs comparable to yours is less }\end{array}$ & $24 \%$ & $20 \%$ & $56 \%$ \\
\hline 4 & Satisfaction with Job Content & $100 \%$ & $0 \%$ & $0 \%$ \\
\hline 5 & Pay Raises & $50 \%$ & $26 \%$ & $24 \%$ \\
\hline 6 & Salary progression & $47 \%$ & $13 \%$ & $40 \%$ \\
\hline 7 & Sense of Belonging & $73 \%$ & $20 \%$ & $7 \%$ \\
\hline 8 & Current Salary & $53 \%$ & $30 \%$ & $17 \%$ \\
\hline 9 & Career Opportunities & $76 \%$ & $14 \%$ & $10 \%$ \\
\hline
\end{tabular}

Question two asked the employees to compare their salaries with one person performing the same work as was performed by the respondent in the same organization and to state if the salary of that employee was greater. This question was asked in order to get information about the level of internal equity in Telenor. The 
employees were asked to compare themselves with an employee in the same organization. The response showed that $44 \%$ of the respondents agreed with the statement which means that when they compared themselves with an employee with a job comparable to his, the employee considered the salary of the other employee greater than his salary. Again this is due to the fact as explains during analysis of question one that employees may have same job but different pay because of the reason that one might be at star-up stage and other with higher skills due to time period with the company. While on the other hand $24 \%$ respondents disagreed to this statement and $32 \%$ stayed neutral which shows that almost more than half of the respondents did not agree with the statement.

Question number three asked about the estimated average annual salary of employees in the respondents region who are holding jobs comparable to theirs is less. The response to this question shows that almost 52\% of the respondents disagreed with this statement showing that the employees at Telenor when compare their annual salaries with those of others in the same region in other organizations, they seem to be considering other organizations to be paying the same or may be more for the same kind of jobs. According to literature equity theory states that employees compare their input and the output they get for that input with those of employees in other organizations. Such comparisons may result in an increase in motivation or it may also have a negative effect on the motivation of employees depending upon the nature of the result that comes out of the comparison, that is, if the employees consider their salary greater than the employees in another organization they will be motivated vice versa. Keeping in view the above description from literature and the data collected from the questionnaires filled by employees of Telenor shows that majority of the employees do not consider their estimated annual salaries greater than those of the employees working in other organizations in the same region. As the question does not give the detailed information about whether they considered their salaries on the same level or lesser than the salaries, that employees get in other organizations so it cannot be directly stated that the employees at Telenor are demotivated or not but it can be inferred from the fact that $48 \%$ employees either stayed neutral or agreed with this statement that the motivation level of the employees is not negatively affected by this comparison.

In question four, the satisfaction with job content was shown by $100 \%$. The question five about the satisfaction over pay raise was reported highly with $50 \%$ agreement followed by six question regarding salary progression satisfaction with $47 \%$ rate of agreement. The employee showed $73 \%$ sense of belonging with Telenor in question number seven. Satisfaction in question eight and nine over current salary and career opportunities were $53 \%$ and $76 \%$ respectively.

In short, the interview and questionnaire data confirmed that pay satisfaction is one of the determinants of job satisfaction. This is the reason that it has a major role in determining organizational effectiveness and the data collected showed that in Telenor equity is in balance and pay satisfaction over various components of total compensation has an overall positive role in creating strong sense of belongininess of employee with Telenor.

5. Conclusion. This study revealed the positive impact of various components of compensation and benefits on pay satisfaction of employees in Telenor company. Among the fixed pay dimensions, merit increments on regular basis were prominent towards the pay satisfaction of employees. Seniority bonuses were not catered because of the fact that the company has a flexible pay structure that of broadband (six bands). Broadband offer flexibility and salary progression becomes easy as employees is not promoted to another grade but moved within band (in-grade promotion). It has importance in contrast to seniority based culture because it empowered employee which results in quick and effective decision making.The variable pay dimensions such as goal based pay, accurate information use related to salary decisions, employee rights concern and information sharing regarding employee related decisions are much satisfactory at Telenor. However, stock options was at least satisfactory level. Majority of employees showed satisfaction over profit sharing policies and short term incentives.It was found that variable pay affect the pay satisfaction of employee positively and it can be increased in case of Telenor if the weak links is given a due consideration. In case of benefits of Telenor, employees were highly satisfied with allowances, welfare programs and considered it important for their stay in Telenor. They acknowledged their desire for enhauncement in benefits. They strongly consider benefit as a part of pay in Telenor and the reason of their motivation and satisfaction. Disability income protection concept is not prevailing in the company. Overall, equity in Telenor is in balance and pay 
satisfaction along various components of total compensation has an overall positive role in creating strong sense of belongininess of employee with their organization.

\section{REFERENCES}

[1] Lawler, E.E. (1995). The new pay: A strategic approach. Compensation \& Benefits Review, 27(4), 14-21.

[2] Heneman, H.G., \& Schwab P. D. (1985). Pay satisfaction: Its multidimensional nature and measurement. International Journal of Psychology, 20(1), 129-141.

[3] Heneman, R.L., Greenberger, D. B., \& Strasser, S. (1988). The relationship between pay for performance perceptions and pay satisfaction. Personnel Psychology, 41, 745-759.

[4] Judge, T.A. \& Welbourne, T.M. (1994). A confirmatory investigation of the dimensionality of the pay satisfaction questionnaire. Journal of Applied Psychology, 79(3), 461-466.

[5] Sweet, J., Nelson, N., \& Moberg, P. (2006). The TCN/AACN 2005 salary survey: Professional practices, beliefs, and incomes of US Neuropsychologists. The Clinical Neuropsychologist, 20(3), 325-364.

[6] Currall, S.C., Towler, A.J., Judge, T.A. and Kohn, L. (2005). Pay satisfaction and organizational outcomes. Personnel Psychology, 58, 613-640.

[7] Naumann, E. (1993). Organizational predictors of expatriate job satisfaction. Journal of International Business Studies, 24(1), 61-80.

[8] Suutari, V. and Tornikoski, C. (2001). The challenge of expatriate compensation: the sources of satisfaction and dissatisfaction among expatriates. International Journal of Human Resource Management, 12(3), 389-404.

[9] Yale D. T., \& Donald R. L. (2002). Executive Compensation. BNA Books.

[10] Rynes, S. L. \& Gerhart, B. (2000). Compensation in organizations: Current research and practice. San Francisco: Jossey-Bass

[11] Henderson, R. I. (2000). Compensation management in a knowledge-based world. Upper Saddle River, NJ: Prentice Hall.

[12] Weathington, B. L. \& Jones, A. P. (2006). Measuring the value of nonwage employee benefits: Building a model of relation between benefit satisfaction and value. Genetic, Social and General Psychology Monographs, 132(4), 292-328.

[13] Deluca, M.J. (1993). Handbook of compensation management. New Jersey, US: Prentice-Hall.

[14] Rajkumar, K. (1996). Paying for performance: Designing effective compensation strategies. Malaysia: Pelanduk Publications.

[15] Milkovich, G.T. \& Newman, J.M. (2008). Compensation (9th Ed.). McGraw Hill International Edition, USA.

[16] Madhani Pankaj M. (2011). Realigning fixed and variable pay : Compensation management. SCMS Journal of Indian Management, 8(1), 5-17

[17] Chaudhry, M. S., Sabir, H. M., Rafi, N., \& Kalyar, M. N. (2011). Exploring the relationship between salary satisfaction and job satisfaction: A comparison of public and private sector organizations. The Journal of Commerce, 3(4), 1-14.

[18] Sharma, J. P., \& Bajpai, N. (2011). Salary satisfaction as an antecedent of job satisfaction: Development of a regression model to determine the linearity between salary satisfaction and job satisfaction in a public and a private organization. European Journal of Social Sciences, 18.

[19] Flaherty, K. E., \& Pappas, J. M. (2002). The influence of career stage on job attitudes: Toward a contingency perspective. Journal of Personal Selling and Sales Management, 22(3), 135-144.

[20] Barber, A. D. (1992). The impact of flexible benefits on employee satisfaction: A field study. Personnel Psychology, 45(1), 55-74.

[21] Hutchinson, P. (2004). Flexible benefits. CIPD

[22] Mckenna, E. F. (2000). Business Psychology and Organization behavior: A Student handbook. London: Psychology Press.

[23] Gerhart, B. \& Milkovich, G.T. (1992). Employee compensation: Research and practice. In Dunnette, M.D. and Hough, M. (Eds), Handbook of Industrial and Organizational Psychology (pp. 481-570), California: Consulting Psychologists Press 
[24] Faulk, L. H. (2002). Pay satisfaction consequences: Development and test of a theoretical model (Doctoral dissertation). Louisiana State University.

[25] Markova, G. F. J. (2011). Attitude formation of benefits satisfaction: knowledge and fit of benefits. Internationl Journal Of Business Research and Management , 2(1),45-52

[26] Adams, J. S. (1963). Wage inequities, productivity and work quality. Industrial Relations, 3, 9-16.

[27] Lawler, E. (1971). Pay and organizational effectiveness: A psychological view. New York: McGraw-Hill.

[28] Vroom, V.H. (1964). Work and Motivation. Wiley, New York.

[29] Igalens, J. and Roussel, P. (1999). A study of the relationships between compensation package, work motivation and job satisfaction. Journal of Organizational Behavior, 20, 1003-1025.

[30] Dreher George F. (1981). Predicting the salary satisfaction of exempt employees. Personnel Psychology, 34 (3), 579-589. 